\title{
Larvicidal Potential of Five Selected Dragonfly Nymphs in Sri Lanka over Aedes aegypti (Linnaeus) Larvae under Laboratory Settings
}

\author{
Chathurika Samanmali, ${ }^{1}$ Lahiru Udayanga $\mathbb{D}^{2,3}$ Tharaka Ranathunge ${ }^{2}{ }^{2}$, \\ Sandun J. Perera, ${ }^{1}$ Menaka Hapugoda, ${ }^{2}$ and Chathura Weliwitiya ${ }^{4}$ \\ ${ }^{1}$ Department of Natural Resources, Faculty of Applied Sciences, Sabaragamuwa University of Sri Lanka, Sri Lanka \\ ${ }^{2}$ Department of Biosystems Engineering, Faculty of Agriculture \& Plantation Management, \\ Wayamba University of Sri Lanka, Sri Lanka \\ ${ }^{3}$ Department of Biosystems, Faculty of Agriculture \& Plantation Management, Wayamba University of Sri Lanka, Sri Lanka \\ ${ }^{4}$ HELPO Eco Green Ltd., Talbot Town, Galle, Sri Lanka
}

Correspondence should be addressed to Tharaka Ranathunge; tharaka.ranathunge@gmail.com

Received 3 August 2018; Revised 4 November 2018; Accepted 19 November 2018; Published 3 December 2018

Academic Editor: Ceferino M. López Sández

\begin{abstract}
Copyright (C) 2018 Chathurika Samanmali et al. This is an open access article distributed under the Creative Commons Attribution License, which permits unrestricted use, distribution, and reproduction in any medium, provided the original work is properly cited.
\end{abstract}

Introduction. Limitations in breeding source reduction practices, development of insecticide resistance in mosquitoes, and ill effects of chemical controlling methods on human and ecosystem health have motivated Sri Lankan authorities working for dengue control to seek for alternative, ecofriendly, and sustainable approaches for controlling of Aedes vectors, to manage dengue epidemics. The present study attempted to investigate the predation efficiency of locally available dragonfly nymphs over Aedes aegypti under laboratory conditions, aiming to evaluate the potential of using dragonflies as biocontrol agents against dengue. Methods. Nymphal stages of five locally abundant dragonfly species were collected from different stagnated water bodies in Belihuloya area. After morphological identification, a well grown individual of each species was starved for 12 hours and introduced into a glass tank containing $1 \mathrm{~L}$ of pond water with 200 larvae (4th instar) of Aedes aegypti. Number of larvae survived in the tank was enumerated hourly up to 48 hours. In case where $>75 \%$ of larvae are consumed by dragonfly nymphs, additional Ae. aegypti larvae were introduced into such tanks. Experiment was repeated for five times. Same procedure was followed with different stages of growth of the dragonfly nymphs characterized by the highest predation rate. General Linear Model followed by Tukey's pairwise comparison was used for statistical analysis. Results. The predation rates of different dragonfly species varied significantly ( $\mathrm{p}<0.05)$, whereby Anax indicus (110 \pm 7.14 per day) indicated the highest, followed by Pantala flavescens $(54.07 \pm 5.15)$ and Gynacantha dravida $(49.00 \pm 11.89)$, while Tholymis tillarga $(23.47 \pm 2.48)$ had the lowest. Further, significant variations in the larval predation were found among different maturity stages $(10-20 ; 25-35$; and $35-45 \mathrm{~mm}$ in body length) of Ana. indicus ( $\mathrm{p}<0.05)$. Regardless of statistical significance, a relatively higher larvicidal activity was observed at dusk than in dawn. Conclusion. Ana. indicus, which is characterized by the highest predation rate, and P. flavescens that has the widest geographical distribution within Sri Lanka along with a notable predation efficacy could be recommended as potential candidates for field trials in biological control of dengue outbreaks via suppression of Ae. aegypti larvae.

\section{Background}

Mosquitoes pose one of the main hazards to human health as they perform a major role in the transmission of vector borne diseases [1]. Among them, dengue is a fast growing mosquitoborne viral disease, which is widely spreading over the world.
About 50 million dengue viral infections occur every year and virtually 2.5 billion people live in dengue endemic countries [2]. Approximately, 1.8 billion people (more than $70 \%$ ) are at risk for dengue viral infection within the member states of the World Health Organization's Western Pacific and SouthEast Asia Regions, which contribute to approximately $75 \%$ 
of the recent global disease burden due to Dengue Fever [3].

Sri Lanka has been affected by epidemics of Dengue Fever (DF) and Dengue Haemorrhagic Fever (DHF) for over two decades. In Sri Lanka, Aedes aegypti remain as the primary vector supported by Ae. albopictus as the secondary vector. Dengue viral infections have been reported from Sri Lanka since the mid-1960s. DF was serologically corroborated in 1962 and the existence of DF in all of the major towns situated below $1200 \mathrm{~m}$ elevation was confirmed within the period of 1976-1978 [4]. With its change in serotype(s), an alarming increase in the incidence of dengue is at play in Sri Lanka, causing the highest ever number of dengue cases as 186, 101 with over 440 deaths in 2017 [5].

Absence of effective drugs and vaccines for the four serotypes of dengue virus has restricted the efficacy of patient management approaches, making vector control and management as the most practical option to control dengue within Sri Lanka. For this, a variety of approaches such as environmental management, chemical control and biological control, etc. are being considered recently. Different, chemical insecticides are being widely used to control adult and larval mosquitoes for many decades, within many countries including Sri Lanka. However, the unintended side effects on human and ecosystem health, development of resistance within mosquitoes, and prominent financial costs have resulted in notable failures in use of chemical based controlling approaches such as larvicides, long-lasting insecticidal nets, Indoor Residual Spraying (IRS), etc. [6-8]. Therefore, authorities working for dengue control seek for alternative, innovative, and ecofriendly methods to reduce both larval and adult vector densities [9]. Among numerous novel strategies, such as Sterile Insect Technique (SIT) and Incompatible Insect Technique (IIT), controlling aquatic larval stages of vector mosquitoes by using their indigenous natural enemies (pathogens, parasites, and predators), also known as biological control, remain as one of the low cost and ecofriendly approach of integrated vector control [9].

Biological control methods attempt to utilize the natural enemies of mosquitoes at different stages of life cycle, both as predators and parasites. A great diversity of living organisms including microbes, fungi, protozoa, nematodes, other invertebrates, and vertebrate predators have been recognized as potential mosquito control agents $[10,11]$. Among different biological controlling agents, predatory insects like damselfly and dragonfly nymphs have gained a high consideration as significant predators of many microinvertebrates including the larvae of Aedes mosquitoes [11-13]. Both damselflies and dragonflies belong to Order Odonata, specifically into suborders Zygoptera and Anisoptera, respectively. At present, a total of 124 species, consisting of 66 species belonging to the suborder Anisoptera and 58 species into the suborder Zygoptera, have been reported from Sri Lanka [14].

Both, the nymph and the adult of these two suborders predate on mosquitoes [1]. High reproduction capacity, adaptability to the introduced environment, preference for the target pest population in the existence of substitute natural prey, and overall interaction with native organisms have been recognized as key characteristics of any biological controlling agent [9]. Among different food preferences of dragonfly nymphs, small larval forms such as Aedes larvae remain preferred by them even in their natural habitats, while adult dragonflies also predate on adult mosquitoes $[15,16]$. Further, Odonates bear no harmful impacts on the humans $[17,18]$. Many countries in the world, especially in the SouthAsian region, have evaluated the practical efficacy of using nymphal Odonates as mosquito control agents. Myanmar $[19]$ and India $[12,20]$ have successfully used a variety of dragonflies as a potential biological resource in regulating the larval populations of vector and pest mosquitoes [18].

Since, 1960s the authorities working for dengue control in Sri Lanka have focused more on the chemical based vector management, while the effort on biological controlling of Aedes is only limited to larvicidal feasibility assessments of few copepod and fish species [21]. Regardless of the remarkable diversity and wide distribution of dragonflies within the country, Sri Lanka has not paid any attention to the dragonflies as a potential biocontrol agent of Aedes mosquitoes. With realization of the restrictions in current vector controlling activities, the country should move towards simple, efficient, and ecofriendly methods of vector management. Therefore, the current study was devised to evaluate the potential of using dragonflies as a biocontrol agent to suppress the vector population of Ae. aegypti aiming towards management of dengue epidemics within the country.

\section{Methods}

2.1. Establishment of Aedes aegypti Colony. An adult mosquito collection was conducted in the Narangodapaluwa Medical Officer of Health ( $\mathrm{MOH})$ area, Ragama, and captured mosquitoes were transported to the laboratory for mass rearing at the Molecular Medicine Unit, Faculty of Medicine, University of Kelaniya, Sri Lanka. Within the laboratory, only the Ae. aegypti mosquitoes were separated through morphological identification by well-trained entomologists. Eggs laid by a single Ae. aegypti blood-engorged female were used to establish a mosquito colony of Ae. aegypti. Each colony was maintained in $24 \times 24 \times 24 \mathrm{~cm}$ cages with mesh screening on top, under a 12:12 (light:dark) cycle at standard conditions (at $27 \pm 2^{\circ} \mathrm{C}$ and $75 \pm 5 \%$ humidity), adhering to the standard protocols suggested by Gunathilaka et al. [22, 23]. Cattle blood was used to feed the mosquitoes through the metal plate feeding technique [23].

The eggs laid by them were allowed to be hatched within 2-3 days after oviposition. The first instar larvae $\left(\mathrm{L}_{1}\right)$ were transferred daily from the oviposition cups to plastic trays $(40 \times 25 \times 6 \mathrm{~cm})$, with $1,000 \mathrm{ml}$ of water, while maintaining a larval density of 750-800 individuals per tray. Approximately $1 \mathrm{ml}$ of a standard larval diet containing tuna meal (50\%), bovine liver powder (36\%), and yeast (14\%), was added to the larval trays twice a day until the larvae were reared up to the 4 th instar stage $\left(\mathrm{L}_{4}\right)$ [23]. Thence formed 4 th instar larvae were used for the predation trials as described below.

2.2. Establishment of Dragonfly Nymph Colonies. Dragonfly nymphs were collected from different stagnated water bodies located within the premises of the Sabaragamuwa University 


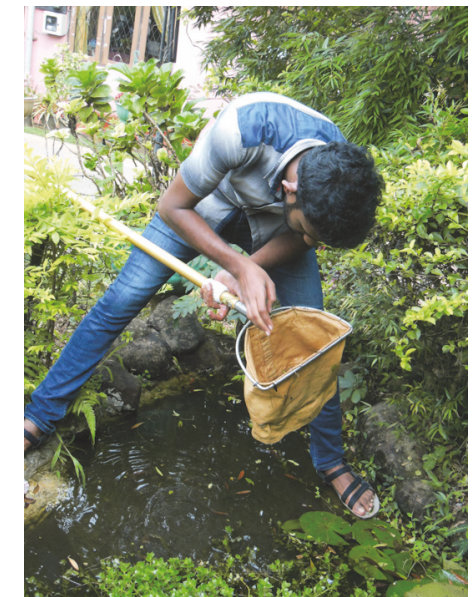

FIgURE 1: Collection of dragonfly larvae with the D-framed net.

of Sri Lanka in Belihuloya. They were collected using a Dframed benthic hand dip net at a depth of one to two feet in stagnated water (Figure 1). The collected nymphs were recorded and transferred into sampling jars provided with water from the same waterbody with water weeds and leaf litter. These sampling jars were carefully to the laboratory. Standard morphological keys described by Fonseka [24] were used for the identification of different dragonfly nymphs up to the species level. The identified nymphs were introduced into glass tanks $(60 \times 30 \times 35 \mathrm{~cm})$ filled with pond and well water from the area at 1:1 ratio, ensuring that different species of dragonfly nymphs are maintained in separate holding tanks. Both protozoan and planktonic algae which are natural sources of food for the dragonfly nymphal stages were provided into the holding tanks via addition of pond water [25]. At least a single individual of each identified species was reared up to the adulthood within the glass tanks under uniform laboratory conditions, while providing stone surfaces near emergence period to further confirm the species identification. Bedjanič et al. [14] used it for species identification of emerging adult specimens.

\section{Predation Experiments}

3.1. Evaluation of the Predatory Efficacy of Different Dragonfly Species. Dragonfly nymphs of different species were reared up to the final instar stage and their body lengths were measured to the closest millimeter by using a ruler. A well grown individual of each species was introduced into separate holding tanks (maintained as described above) and was starved for 12 hours [13]. Hundred 4th instar larvae of Aedes aegypti reared under laboratory settings were introduced into each glass tank initially, while a similar glass tank without any dragonfly nymphs was used as the control. In case where more than $75 \%$ of Aedes larvae were predated, new batches of 4 th instar larvae were introduced into the glass tanks to maintain the 100 individuals per tank larval density throughout a day. After completion of 24 hours, another 100 Ae. aegypti larvae were introduced into each tank. The number of surviving mosquito larvae in each tank was enumerated at 1 hour intervals until 48 hours with minor modifications to the methodology described by Singh et al. [25] and Shad and Andrew [1]. The whole experiment was repeated for five times to maintain the accuracy of the findings.

3.2. Effect of the Nymphal Stage of the Dragonfly Nymph on the Predatory Efficacy. The dragonfly species with the highest nymphal predation rate were recognized from the above experiment (i.e., Anax indicus). The total length of the dragonfly nymph, measured to the closest millimeter by using a ruler, was used to classify the nymphal stage into three classes as (a) initial stage (10-20 mm of total body length in the case of Ana. indicus); (b) medium stage (25-35 mm), and (c) matured stage $(35-45 \mathrm{~mm})$. The above setup was replicated five times with each of the three different body sized dragonfly nymphs of the species found to have the highest predation efficacy.

3.3. Data Interpretation and Statistical Analysis. The predation rates were calculated as the deducted product of remaining mosquito larvae from the initial/earlier surviving larvae. The predation rates of each studied dragonfly nymph on Ae. aegypti larvae were entered into a Microsoft Excel Work Sheet. The significance in the total and hourly average predation rates of dragonfly nymphs were statistically evaluated by using the General Linear Model (GLM) followed by Tukey's pairwise comparison in SPSS (version 23). The Bray Curtis Similarity based Cluster analysis followed by Analysis of Similarities (ANOSIM) (i.e., a nonparametric analog of MANOVA) was utilized to identify the overall clustering status of the studied dragonflies in terms of their predation patterns using the Plymouth Routines in Multivariate Ecological Research version 6 (PRIMER 6) software [26].

\section{Results}

4.1. The Predatory Efficacy of Nymphs of Different Dragonfly Species on Aedes aegypti Larvae. Nymphs of five dragonfly species, namely, Anax indicus, Gynacantha dravida, Orthetrum sabina sabina, Pantala flavescens, and Tholymis tillarga, were identified from the field collections to be used for the predatory efficacy evaluation (Figure 2). G. dravida showed the longest length at the final instar stage $(3.10 \pm$ 0.18 ), while the lowest length of $1.55+0.12$ was shown by P. flavescens (Table 1). Further, the results of the Ae. aegypti larval consumption by nymphs of different dragonfly species are summarized in Table 1. Among the five dragonfly species, Ana. indicus indicated the highest predation of $110 \pm 7.14$ (Mean $\pm \mathrm{SE})$ Ae. aegypti larvae within 24 hours, with an average hourly consumption rate of $4.58 \pm 0.29$ (Mean \pm SE) Ae. aegypti larvae. On the other hand, T. tillarga denoted the lowest larval consumption of $23.47 \pm 2.48$ (Mean \pm SE) Ae. aegypti larvae within 24 hours (Table 1). As suggested by the results of the General Linear Model, the predatory efficiencies of the five dragonfly species varied significantly $(\mathrm{p}<0.05$ at 95\% level of confidence).

Results of the Tukey's pairwise comparison (post hoc analysis) clearly denoted that the predatory efficacies of $P$. 
TABLE 1: Mean number of Aedesaegypti larvae consumed by different dragonfly species in 24 hours.

\begin{tabular}{|c|c|c|c|}
\hline \multirow{2}{*}{ Dragonfly Species } & \multirow{2}{*}{ Mean Length } & \multicolumn{2}{|c|}{$\begin{array}{l}\text { Mean Number of Aedes aegypti larvae } \\
\text { consumed by a dragonfly larva }\end{array}$} \\
\hline & & $\begin{array}{c}\text { Total number of larvae } \\
\text { consumed within } 24 \text { hours }\end{array}$ & $\begin{array}{l}\text { Average number of larvae } \\
\text { consumed within } 1 \text { hour }\end{array}$ \\
\hline Anax indicus & $\begin{array}{l}2.87 \pm 0.10 \\
(2.77-2.97)\end{array}$ & $\begin{array}{l}110.00 \pm 7.14^{\mathrm{a}} \\
(102.86-117.14)\end{array}$ & $\begin{array}{l}4.58 \pm 0.29^{\mathrm{a}} \\
(4.29-4.87)\end{array}$ \\
\hline Pantala flavescens & $\begin{array}{c}1.55 \pm 0.12 \\
(1.43-1.67)\end{array}$ & $\begin{array}{l}54.07 \pm 5.15^{b} \\
(48.92-59.22)\end{array}$ & $\begin{array}{l}2.31 \pm 0.22^{b} \\
(2.09-2.53)\end{array}$ \\
\hline Gynacantha dravida & $\begin{array}{c}3.10 \pm 0.18 \\
(2.92-3.28)\end{array}$ & $\begin{array}{c}49.00 \pm 11.89^{b} \\
(37.11-60.89)\end{array}$ & $\begin{array}{c}2.20 \pm 0.49^{b} \\
(1.71-2.69)\end{array}$ \\
\hline Orthetrum sabina sabina & $\begin{array}{l}1.60 \pm 0.18 \\
(1.42-1.78)\end{array}$ & $\begin{array}{l}26.87 \pm 2.89^{c} \\
(23.98-29.76)\end{array}$ & $\begin{array}{l}1.09 \pm 0.12^{c} \\
(0.97-1.21)\end{array}$ \\
\hline Tholymis tillarga & $\begin{array}{l}1.57 \pm 0.09 \\
(1.48-1.66)\end{array}$ & $\begin{array}{l}23.47 \pm 2.48^{c} \\
(20.99-25.95)\end{array}$ & $\begin{array}{l}0.95 \pm 0.10^{d} \\
(0.85-1.05)\end{array}$ \\
\hline
\end{tabular}

Note: values are Mean \pm SE, range in parenthesis. Different superscript letters in a column show significant differences $(\mathrm{p}<0.05)$ as suggested by General Linear Modelling followed by the Tukey's pair wise comparison at $95 \%$ level of significance.

flavescens and G. dravida did not differ significantly ( $\mathrm{p}>0.05$ at $95 \%$ level of confidence), which differed significantly from that of Ana. Indicus ( $\mathrm{p}<0.05)$. Meanwhile, O. sabina sabina and T. tillarga had the lowest predatory efficacies, which were statistically significant from the rest $(\mathrm{p}<0.05)$. Therefore, formation of three major clusters as Anax indicus; P. flavescens and G. dravida together; and O. sabina sabina and T. tillarga together could be recognized based on the predatory consumption of Aedes aegypti larvae as suggested by the GLM (Table 1).

The dendrogram of the cluster analysis (based on Bray Curtis Similarity) also suggested the emergence of three clusters of dragonflies as Ana. indicus being the first cluster, while P. flavescens and G. dravida form the second (with a similarity of $96.6 \%$ among each other). Meanwhile, O. sabina sabina and T. tillarga created the third cluster sharing a similarity of $97.1 \%$ based on the total and hourly average predation rates of the studied dragonfly nymphs on Ae. aegypti larvae (Figure 3). Further, the dragonflies of second and third clusters shared a similarity of $81.4 \%$ among them in terms of their predatory rates. The clustering status of the above dendrogram was further confirmed to be statistically significant by the Global $\mathrm{R}$ value of 0.97 ( $\mathrm{p}<0.05$ at $95 \%$ level of confidence) from the Analysis of Similarities (ANOSIM). Therefore, the results of the General Linear Model regarding the significant variations of the predatory efficacies of the studied dragonflies were reassured by cluster analysis and ANOSIM.

4.2. The Predation Efficiency of Different Nymphal Stages of Anax indicus on Aedes aegypti Larvae. Ana. indicus nymphs reported the highest predatory efficacy on Ae. aegypti larvae from the current study. Therefore, the current study investigated the effect of larval body size of Ana. indicus (in terms of body length) on the predatory efficiency. The mean number of Ae aegypti larvae consumed by Ana. indicus varied significantly according to the body size of the dragonfly larvae $(\mathrm{p}<0.05$, at $95 \%$ level of significance).

The Ana. indicus nymphs with relatively larger body size $(35-45 \mathrm{~mm})$ indicated the highest predation, of $214.00 \pm 13.20$ as the total larval consumption within 24 hours along with, an hourly average of $8.92 \pm 0.55$ Ae. aegypti larvae. Meanwhile, the smallest $(25-35 \mathrm{~mm})$ Ana. indicus larvae denoted the lowest predation rates of $52.87 \pm 5.34$ Ae. aegypti larvae, under similar laboratory conditions (Table 2).

\subsection{Temporal Variations in the Predation of Anax indicus on Ae. aegypti Larvae}

4.3.1. Diurnal Changes in Predation. Due to being the best performer with the highest predation rates, the diurnal changes of the predatory action of Ana. indicus on Ae. aegypti mosquito were further investigated. As denoted by Figure 4, the predation rates of Ana. indicus were almost similar in both day $(6.00 \mathrm{am}$ to $6.00 \mathrm{pm})$ and night $(6.00 \mathrm{pm}$ to 6.00 am). However, it should be highlighted that only a limited number of replicates were carried out $(n=5)$, which may be insufficient to arrive at a reasonable conclusion on the temporal variations of predatory rates of Ana. indicus, in terms of day and night.

4.4. Hourly Temporal Variation of the Anax indicus Larval Predation on Aedes aegypti Larva. In case of the hourly temporal variations of the predation rates of Ana. indicus nymphs on the larvae of Ae. aegypti, two mild peaks of predation were observed in the dawn (6.00 a.m. to 9.00 a.m.) and dusk (3.00 p.m. to 6.00 p.m.) Among them, the highest predation rate was observed at the dusk. However, as indicated by Figure 5, significant variations in the hourly predation rates were not noted for Ae. aegypti larval consumption by Ana. indicus.

\section{Discussion}

Being one of the major health threats in Sri Lanka, dengue is challenging the health sector of the country with severe cyclic epidemics. The current vector control methods that mainly focus on the chemical based control of vectors with less emphasis on community involved vector management seem to have a limited success in managing the outbreaks of dengue 


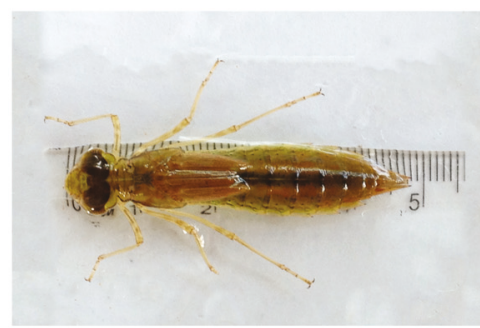

Anax indicus

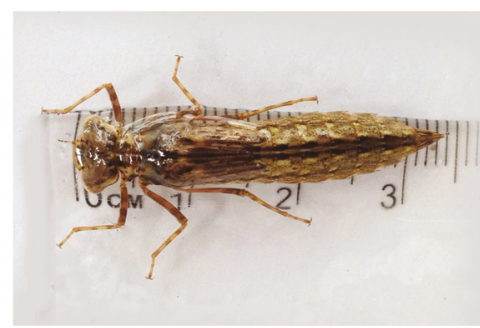

Gynacantha dravida

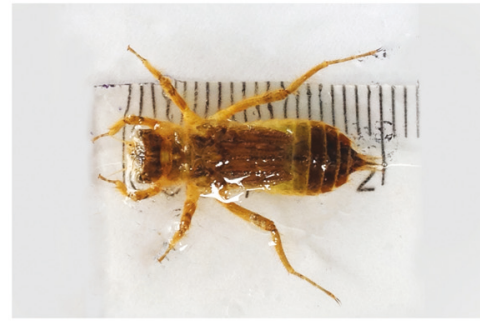

Orthetrum sabina sabina

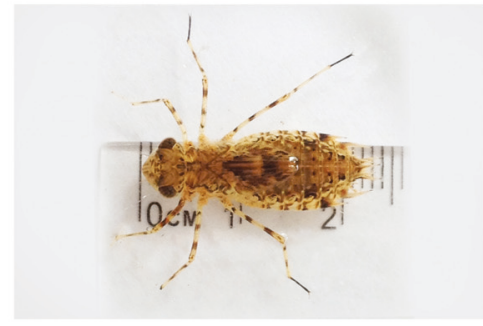

Pantala flavescens

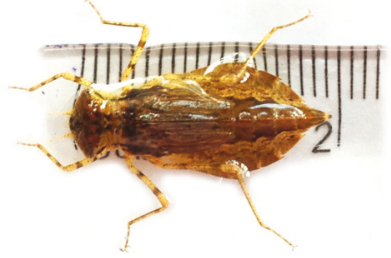

Tholymis tillarga

FIGURE 2: Different dragonfly larval species evaluated during the predation experiments.

TABLE 2: Mean number of Aedes aegypti larvae consumed by Anax indicus (the best performer, in terms of larval predation) with different body size categories.

\begin{tabular}{lcc}
\hline $\begin{array}{l}\text { Body size/Maturity } \\
\text { categories }\end{array}$ & \multicolumn{2}{c}{$\begin{array}{c}\text { Mean Number of Aedes aegypti larvae consumed by } \\
\text { Anax indicus }\end{array}$} \\
\hline Large/Initial & $\begin{array}{c}\text { Total number of larvae } \\
\text { consumed within 24 hours }\end{array}$ & $\begin{array}{c}\text { Average number of larvae } \\
\text { consumed within } \mathbf{1} \text { hour }\end{array}$ \\
$(35-45 \mathrm{~mm})$ & $214.00 \pm 13.20^{\mathrm{a}}$ & $8.92 \pm 0.55^{\mathrm{a}}$ \\
Medium/Medium & $(200.80-227.20)$ & $(8.37-9.47)$ \\
$(25-35 \mathrm{~mm})$ & $110.00 \pm 7.14^{\mathrm{b}}$ & $4.58 \pm 0.30^{\mathrm{b}}$ \\
Small/Matured & $(102.86-117.14)$ & $(4.28-4.88)$ \\
$(10-20 \mathrm{~mm})$ & $52.87 \pm 5.34^{\mathrm{c}}$ & $2.20 \pm 0.22^{\mathrm{c}}$ \\
\hline
\end{tabular}

Note: values are Mean \pm SE, range in parenthesis. Different superscript letters in a column show significant differences $(p<0.05)$ as suggested by General Linear Modelling followed by the Tukey's pair wise comparison at $95 \%$ level of significance. 


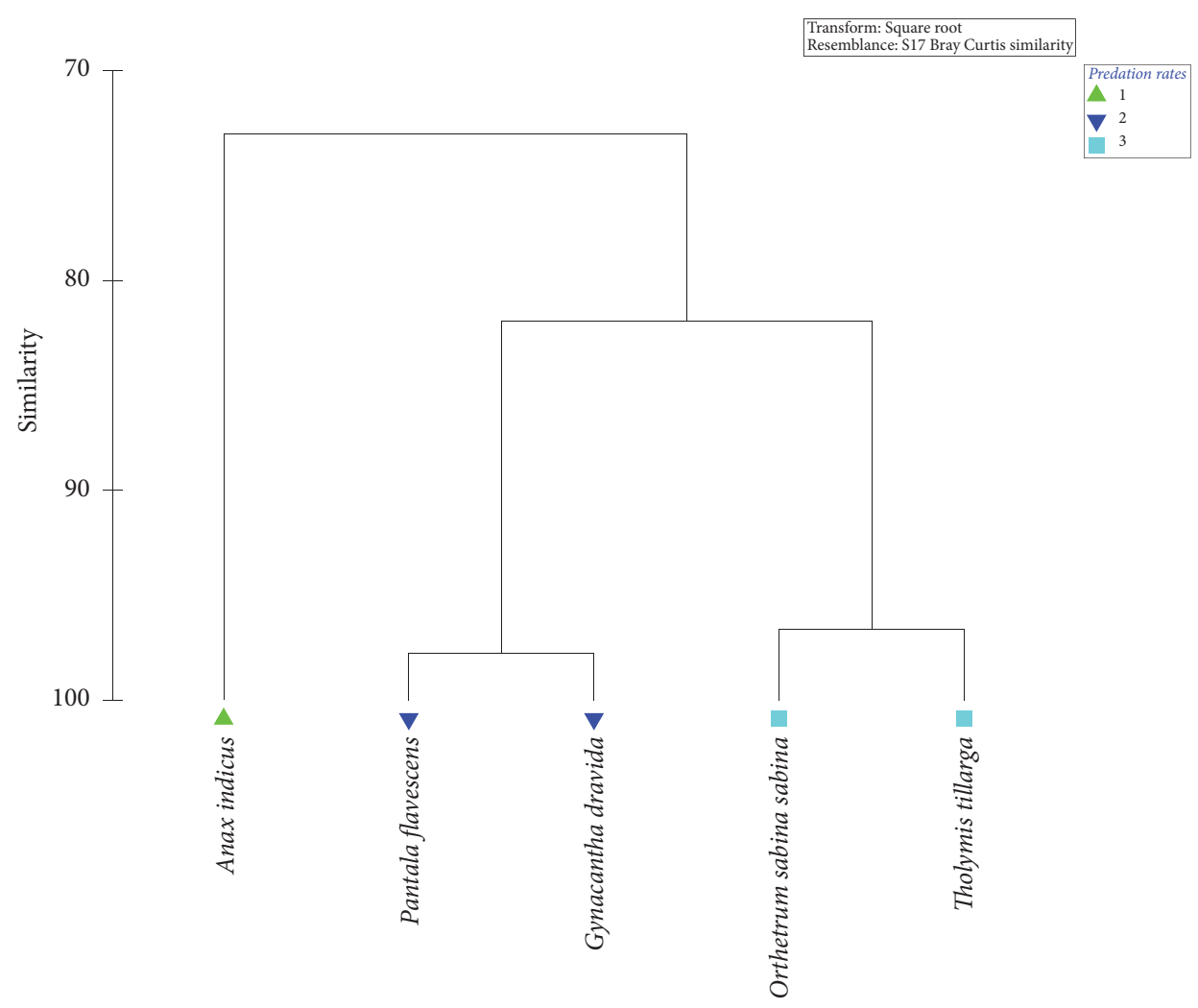

FIGURE 3: Dendrogram of the cluster analysis of the dragonflies in terms of the Aedes larval consumption patterns.

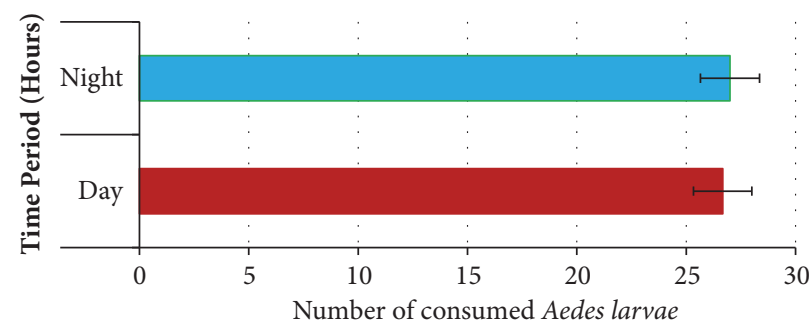

FIGURE 4: Diurnal changes in the Aedes aegypti mosquito larval consumption by Anax indicus (the best performer).

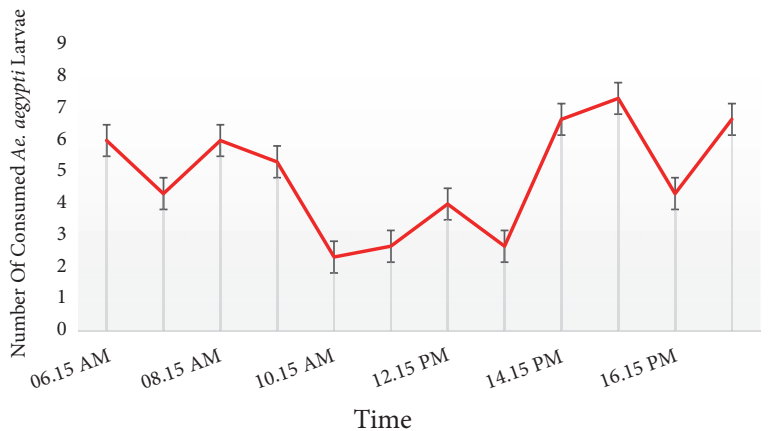

Figure 5: Temporal variation of the hourly average number of Aedes aegypti mosquito larvae consumed by Anax indicus (the best performer).

[27]. Therefore, evaluation of the efficacy of novel vector control methods such as the use of different biological control agents is of essence to address the burning issue of dengue $[1,20,25]$. Dragonflies have shown promising results in this aspect and have been used in many neighboring counties with similar environmental and socioeconomic settings [12, $13,25]$.

According to the current study, it was apparent that Anax indicus, P. flavescens, G. dravida, O. sabina sabina, and T. tillarga are active feeders and able to consume Ae. aegypti mosquito larvae in notable quantities under laboratory conditions. Results of the predation experiment indicated that Ana. indicus of Family Aeshnidae showed the highest predation. Ana. indicus generally oviposits in richly vegetated tanks and lakes in the dry lowlands of the island and in montane areas, where suitable still water habitats are present making it one of the abundant dragonfly species in rural and semiurban environments [28]. However, the availability of such habitats is limited in urban settings, highlighting the need for conservation of lowland wetlands 
and other stagnated aquatic habitats, to promote the natural distribution of this species as a biological control agent against dengue vectors. A study conducted by Becker et al. [29] has reported a similar predation potential of around 100 mosquito larvae by Anisopteran nymphs, suggesting it as an effective biological control agent. Thus, based on the current findings Ana. indicus could also be identified as an excellent candidate for biocontrol of dengue vectors.

Both G. dravida and Ana. indicus are members of Aeshnidae, which are commonly known as hawkers. G. dravida is distributed over low country, covering both wet and dry zones around swamps and tanks with weedy vegetation, and is often found inside houses as it is attracted to lights at night. The adults of those remain mostly active at dusk [28]. Therefore, this species has a high potential for predating upon both larvae and adults of Aedes mosquitoes, during its larval and adult stages in reducing Aedes populations.

$P$. flavescens, of the Family Libellulidae, which remains as the most common and widespread dragonfly species in Sri Lanka and possibly the most ubiquitous in the whole world [14], indicated the second highest predation rates of Aedes larvae. It is cosmopolitan and migrates in large numbers with the monsoon winds and are distributed all over Sri Lanka dwelling in open habitats including paddy fields, tanks, marshes, rivers, grasslands, lagoons, scrub forests, and large forest gaps [30]. Further, it is one of the most opportunistic breeders, which can breed in different conditions, ranging from muddy water pits to discarded containers in urban environments. In addition to the extreme dispersal ability, $P$. flavescens is characterized by a very rapid larval development rate, which often completes in just over one month [28]. Therefore, $P$. flavescens, which almost habitually breeds in every habitat, also remain as an ideal candidate to be used as a biological control agent against dengue vectors, due to the ability to adapt to various water bodies that are scattered within and around human settlements. In addition, O. sabina sabina and T. tillarga that showed relatively lower rates of predation in comparison to the other dragonfly nymphs also have a wider geographical distribution in Sri Lanka, occupying all types of wetlands found in the country [28].

Current study used 4th instar of Ae. aegypti mosquito larvae for all the predation experiments, since it remains as the larval stage with the highest body size. However, a previous study has reported that the predatory impact of Bradinopyga geminata on Ae. aegypti larvae was higher in 1st instar larvae than the other late instars, probably due to the smaller body size [12]. Another similar study has revealed that feeding rate of $B$. contaminate on aquatic stages of Anopheles stephensi, Culex quinquefasciatus, and Ae. aegypti also showed a similar trend, where the maximum predation was observed for the 1st instar larvae [25].

According to Córdoba-Aguilar and Lee [13], both smaller and larger dragonfly nymphs predate on bigger prey at high densities of prey. As shown by their findings, Orthemis ferruginea (fabricius) dragonfly larvae (Family: Libellulidae) predate on 4th instar Ae. aegypti mosquitoes than the 1st instar and pupae, especially by the smaller body sized predators. Although 4th instars are not larger than pupae, their shape might make them seem larger for predators. Therefore, a dragonfly's predation choice may be influenced by the shape and movement as well as the size of prey. The 4 th instar mosquitoes are more active as well as larger than other three mosquito larval instar levels. Only smaller predators feed significantly more on the biggest prey at similar densities of different sizes of prey, while bigger dragonfly nymphs did not show a size preference [13]. This may be accounted by the high energy requirement of smaller sized dragonfly larvae due to their urge in completing the development stages in the life cycle.

However, in the current study, Ana. indicus with relatively larger body size $(35-45 \mathrm{~mm})$ indicated the highest predation of $214.00+13.20$ as the total larval consumption. Several studies that evaluated the predation of Orthemis spp. have shown that dragonfly nymphs with large body size predate upon mosquito larvae with no preference for the immature stages of mosquito [31, 32]. Further, findings of Chatterjee et al. agree with the current findings by highlighting that small sized nymphs of Brachytron pratense were not interested to prey upon fourth instar stage of mosquito larvae in laboratory, without prolonged starvation [33]. Therefore, the variations in the gape size of the dragonfly nymphs that occur with advancement of age may have resulted in the high predation of 4th instar larvae by larger body sized nymphs.

The diurnal variation in the predation of Ana. indicus dragonfly larvae on Ae. aegypti larvae did not differ significantly within the present study. The findings of the current study stand in line with that of Córdoba-Aguilar and Lee, who also showed that there is no significant difference in the predation in dark and light conditions of Orthemis ferruginea against $A$ e. aegypti larvae [13]. Interestingly, in the present study, the predation of Ana. indicus was slightly higher at dawn and dusk, while predation was lower at the mid-day period. Further, the highest predation rate was observed at the dusk, regardless of the absence of significant variations in the hourly predation rates. Similar findings have been reported by Venkatesh and Tyagi, whereby the percentage consumption of Ae. aegypti larvae by Bradinopyga geminate remained with no marked diurnal variation [12]. Moreover, a relatively high predation rate of mosquito larvae in darkness (which was not statistically significant) has been evidenced for Tramea spp. [31]. On the other hand, a previous study conducted by Mandal et al. has highlighted a significant diurnal variation of $C x$. quinquefasciatus predation, indicating a lower predation rate at night [19].

Usually, dragonfly nymphs belonging to the genus Anax are highly adapted surface feeders, and their diurnal rhythm of feeding has been attributed to various facts in the literature [24]. The flicker frequency for response of those is found to be associated with the intensity of light, while the mean critical illumination is progressively shifted towards higher intensities at the lower ambient temperatures [28]. Therefore, the progressive increase in significance of the eyes might be expected to have affected the diurnal rhythm of feeding activity, regardless of the statistically nonsignificance of predation rates. Further, the genus Anax is known to indicate a circadian rhythm of locomotory activity, which is entrained by the interchanging light-dark cycle. They have been reported to walk slowly over the bottom at night, instead of moving by 
jet propulsion during day time, enabling them to have a more probability of finding mosquito larvae as prey [24].

A number of parameters have been found to influence the predation rates and biocontrol efficacy of dragonfly nymphs on Aedes larvae. Increasing larval size and instar stage of the prey (Aedes larvae) [12], size, maturity stage, and energy requirements of the predator (dragonflies) along with and other physiological attributes of predators [34-36] tend to affect the above said predation rates. Further, several environmental factors such as temperature, illumination, container size, and foraging area could also affect the mosquito larval consumption by dragonflies [1]. The survival, development, and recruitment levels of mosquitoes (from immature stages to adult vector populations) are highly influenced by predaceous insects, especially by dragonflies. Therefore, detaining of the immature stages of vectors in most of the aquatic habitats has maintained vector densities below the critical thresholds, leading to control of epidemic incidence [3739]. Several semifield studies have highlighted the efficacy of using different dragonfly larval species as a biocontrolling agent to suppress variety of vector mosquito populations such as Anopheles subpictus [37], Ano. stephensi [39], Ae. aegypti [12, 20, 39], and Cx. quinquefasciatus [19]. Based on the findings of the present study, Anax indicus that denoted the highest predation rate for Ae. aegypti is recommended as a biocontrol agent for controlling of dengue through introduction into the field. Further, P. flavescens which was characterized by the second highest biocontrol efficacy could also be focused on which may be as a better candidate for field trials due to its wide geographical distribution and ability of completing the life cycle within a relatively short period in different habitats, especially in urban environments $[24,28]$.

Use of dragonflies as a biological control agent against Aedes vectors would essentially be a key solution to control dengue, due to their ability to kill target species, safety awarded to nontarget organisms, easy application in the field, inexpensive production, lack of infectivity, and no pathogenicity in mammals including man $[12,13,40]$. The success and sustainability of such biocontrol activities heavily depend upon the land use practices and development activities. Poorly planned development activities that occur within urban and semiurban areas in the country may directly contribute to the occurrence of breeding sites for dengue vectors, while diminishing the quality of potential breeding habitats of dragonflies [27, 40]. Therefore, in order to reduce population of Aedes mosquitoes through biocontrolling by dragonfly larvae, it is essential to conserve breeding habitats such as paddy fields, tanks, marshes, rivers, grasslands, lagoons, scrub forests, and large tracts of forest [29]. However, facilitation of the P. flavescens populations might be an ideal solution, due to its ability of breeding in numerous urban habitats scattered within and around human settlements. Therefore, it is suggested to conduct further research on the biocontrol efficacy of Ana. indicus and $P$. flavescens under semifield and field conditions as a pioneering project to evaluate the practical feasibility of suppressing Aedes vector populations by the use of dragonflies within Sri Lanka.

\section{Conclusions}

The predatory efficacy of the studied dragonflies on Ae. aegypti larvae differed significantly $(\mathrm{p}<0.05$, at $95 \%$ level of significance). Ana. indicus showed the highest predation efficiency (110 \pm 7.14 per day) followed by $P$. flavescens (54.07 \pm 5.15$)$. The predation efficiency of Ana. indicus significantly varied according to the maturity level (body size) of the dragonfly nymphs $(\mathrm{p}<0.05)$, whereby larger body sized dragonfly nymphs indicated the maximum predation rate of $214.00 \pm 13.20$ Ae. aegypti larvae within 24 hours. Regardless of the absence of statistically significant variations in the diurnal variations in predation rates, a relatively high predation was observed at dusk.

In Sri Lanka, P. flavescens and Ana. indicus indicate relatively wider distribution along with high feasibility for adaptation. Therefore, the study recommends Ana. indicus and $P$. flavescens as potential candidates for a field trial of biological control of dengue via suppressing of vector populations. It can be recommended for the authorities working for dengue control in Sri Lanka to incorporate the introduction and facilitation of the dispersion of above dragonfly species as key steps in Integrated Vector Management (IVM) approaches to control the incidence of dengue viral outbreaks.

$\begin{array}{ll}\text { Abbreviations } \\ \text { ANOSIM: } & \text { Analysis of Similarities } \\ \text { DF: } & \text { Dengue Fever } \\ \text { DHF: } & \text { Dengue Haemorrhagic Fever } \\ \text { GLM: } & \text { General Linear Model } \\ \text { IIT: } & \text { Incompatible Insect Technique } \\ \text { IVM: } & \text { Integrated Vector Management } \\ \text { IRS: } & \text { Indoor Residual Spraying } \\ \text { MANOVA: } & \text { Multivariate Analysis of Variance } \\ \text { MOH: } & \text { Medical Officer of Health } \\ \text { PRIMER: } & \text { Plymouth Routines in Multivariate } \\ & \text { Ecological Research } \\ \text { SIT: } & \text { Sterile Insect Technique } \\ \text { SPSS: } & \text { Statistical Package for the Social Sciences } \\ \text { WHO: } & \text { World Health Organization. }\end{array}$

\section{Data Availability}

The data used to support the findings of this study are included within the article.

\section{Conflicts of Interest}

The authors declare that they have no conflicts of interest.

\section{Authors' Contributions}

Chathurika Samanmali conducted laboratory experiments; Tharaka Ranathunge designed the research, supervised laboratory experiments, and wrote the manuscript; Lahiru Udayanga supervised the research, performed statistical analyses, and wrote the manuscript; Sandun J. Perera supervised 
the research, especially the field component, and reviewed the manuscript; Menaka Hapugoda supervised the laboratory experiments; all authors read and approved the final manuscript.

\section{Acknowledgments}

Professor J.M.C.K. Jayewardene of the Faculty of Faculty of Applied Sciences, Sabaragamuwa University of Sri Lanka, is acknowledged for her insights and suggestions on the current study. Further, support provided by M. Madhushika Wijesooriya, R. D. Malith Gimhana Jayalath, and Janani Wasana Heenipallage of the Department of Natural Resources, Sabaragamuwa University of Sri Lanka, for the field collection of dragonfly nymphs is appreciated. Technical cooperation for the insectary activities by the IAEA TC SRL 5/057 is also acknowledged.

\section{References}

[1] A. Shad and J. Andrew, "Original Research Article A Study on the Predatory Potency of Dragonfly, Bradinopyga geminata Nymphs over the Immature Stages of the Filarial Vector, Culex quinquefasciatus Say," International Journal of Current Microbiology and Applied Sciences, vol. 2, no. 4, pp. 172-182, 2013.

[2] World Health Organization (WHO), Special Programme for Research, Training in Tropical Diseases, World Health Organization, vol. 8, Epidemic, Pandemic Alert. Dengue: guidelines for diagnosis, treatment, prevention and control, 2016.

[3] S. Bhatt, P. W. Gething, O. J. Brady et al., "The global distribution and burden of dengue," Nature, vol. 496, no. 7446, pp. 504-507, 2013.

[4] P. D. N. N. Sirisena and F. Noordeen, "Evolution of dengue in Sri Lanka-changes in the virus, vector, and climate," International Journal of Infectious Diseases, vol. 19, no. 1, pp. 6-12, 2014.

[5] Epidemiology Unit and Ministry of Health, "Dengue update," 2018, http://www.epid.gov.lk/web/index.php?Itemid=448\#.

[6] K. Walker and M. Lynch, "Contributions of Anopheles larval control to malaria suppression in tropical Africa: review of achievements and potential," Medical and Veterinary Entomology, vol. 21, no. 1, pp. 2-21, 2007.

[7] J. A. Nájera, M. González-Silva, and P. L. Alonso, "Some lessons for the future from the global malaria eradication programme (1955-1969)," PLoS Medicine, vol. 8, no. 1, 2011.

[8] K. P. Paaijmans, W. Takken, A. K. Githeko, and A. F. G. Jacobs, "The effect of water turbidity on the near-surface water temperature of larval habitats of the malaria mosquito Anopheles gambiae," International Journal of Biometerology, vol. 52, no. 8, pp. 747-753, 2008.

[9] R. Kumar and J. S. Hwang, "arvicidal efficiency of aquatic predators: a perspective for mosquito biocontrol," Zoological Studies. Taipei, vol. 45, no. 4, p. 447, 2006.

[10] E. A. Shaalan and D. V. Canyon, "Aquatic insect predators and mosquito control," Tropical Biomedicine, vol. 26, pp. 223-261, 2009.

[11] B. K. Tyagi, A. Munirathinam, and A. Venkatesh, "A catalogue of Indian mosquitoes," International Journal of Mosquito Research, vol. 2, no. 2, pp. 50-97, 2015.

[12] A. Venkatesh and B. K. Tyagi, "Predatory potential of Bradjnopyga geminata and Ceriagrion coromandelianum larvae on dengue vector Aedes aegypti under controlled conditions (Anisoptera: Libellulidae; Zygoptera: Coenagrionidae; Diptera: Culicidae)," Odonatologica, vol. 42, no. 2, pp. 139-149, 2013.

[13] A. Córdoba-Aguilar and M. Lee, "Prey Size Selection by Orthemis Ferruginea (Fabricius) Larvae (Odonata: Libellulidae) over mosquito instars," Folia Entomológica Mexicana, vol. 30, Article ID 91323, 1994.

[14] M. Bedjanič, K. Conniff, and G. De Silva Wijeyeratne, "Gehan's Photo Guide. A Photographic Guide to the Dragonflies of Sri Lanka," Jetwing Eco Holidays, 2007.

[15] M. R. Ellis and S. ladeau, Influence of dragonfly larvae on mosquito development and survival, Cary Institute of Ecosystem Studies, Millbrook, NY, USA, 2013, 12545.

[16] E. C. Bay, "Predator-Prey Relationships Among Aquatic Insects," Annual Review of Entomology, vol. 19, no. 1, pp. 441453, 1974.

[17] A. Mannan, S. Waheed, A. Rahman, S. Ahmad, and I. H. Qureshi, "Multi-element analysis of coastal marine sediment, an IAEA proposed reference material (IAEA-356)," Geostandards and Geoanalytical Research, vol. 17, no. 2, pp. 223-226, 1993.

[18] S. K. Mandal, A. Ghosh, I. Bhattacharjee, and G. Chandra, "Biocontrol efficiency of odonate nymphs against larvae of the mosquito, Culex quinquefasciatus Say, 1823," Acta Tropica, vol. 106, no. 2, pp. 109-114, 2008.

[19] A. Sebastian, M. M. Sein, M. M. Thu, and P. S. Corbet, "Suppression of Aedes aegypti (Diptera: Culicidae) using augmentative release of dragonfly larvae (Odonata: Libellulidae) with community participation in Yangon, Myanmar," Bulletin of Entomological Research, vol. 80, no. 2, pp. 223-232, 1990.

[20] C. Kamaraj, A. A. Rahuman, and A. Bagavan, "Antifeedant and larvicidal effects of plant extracts against Spodoptera litura (F.), Aedes aegypti L. and Culex quinquefasciatus Say," Parasitology Research, vol. 103, no. 2, pp. 325-331, 2008.

[21] B. Manna, G. Aditya, and S. Banerjee, "Habitat heterogeneity and prey selection of Aplocheilus panchax: An indigenous larvivorous fish," Journal of Vector Borne Diseases, vol. 48, no. 3, pp. 144-149, 2011.

[22] P. Gunathilaka, U. Uduwawala, N. Udayanga, R. Ranathunge, L. Amarasinghe, and W. Abeyewickreme, "Determination of the efficiency of diets for larval development in mass rearing Aedes aegypti (Diptera: Culicidae)," Bulletin of Entomological Research, vol. 108, no. 05, pp. 583-592, 2018.

[23] N. Gunathilaka, T. Ranathunge, L. Udayanga, and W. Abeyewickreme, "Efficacy of Blood Sources and Artificial Blood Feeding Methods in Rearing of Aedes aegypti (Diptera: Culicidae) for Sterile Insect Technique and Incompatible Insect Technique Approaches in Sri Lanka," BioMed Research International, vol. 2017, 2017.

[24] T. D. Fonseka, Dragonflies of Sri Lanka, WHT Publications, 2000.

[25] R. K. Singh, R. C. Dhiman, and S. P. Singh, "Laboratory studies on the predatory potential of dragon-fly nymphs on mosquito larvae," Journal of Communicable Diseases, vol. 35, no. 2, pp. 96101, 2003.

[26] K. R. Clarke and R. M. Warwick, "Change in marine communities," An Approach to Statistical Analysis and Interpretation, 2001.

[27] L. Udayanga, N. Gunathilaka, M. C. M. Iqbal, K. Pahalagedara, U. S. Amarasinghe, and W. Abeyewickreme, "Socio-economic, Knowledge Attitude Practices (KAP), household related and 
demographic based appearance of non-dengue infected individuals in high dengue risk areas of Kandy District, Sri Lanka," BMC Infectious Diseases, vol. 18, no. 1, 2018.

[28] M. Bedjanic, K. Conniff, N. Van der Poorten, and A. Šalamun, Dragonfly fauna of Sri Lanka: distribution and biology, with threat status of its endemics, Pensoft, 2014.

[29] N. Becker, D. Petrić, C. Boase et al., Mosquitoes and Their Control, Springer, Boston, MA, USA, 2003.

[30] R. J. Andrew, K. A. Subramanian, and A. D. Tiple, A Handbook on Common Odonates of Central India, Hislop College, 2008.

[31] E. B. Lee and L. Markus, Foundations of optimal control theory, Robert E. Krieger Publishing Co., Inc., Melbourne, FL, Second edition, 1986.

[32] A. A. Cordoba and M. Lee, "Prey size selection by Orthemis ferruginea (Fabricius) larvae (Odonata: Libellulidae) over mosquito instar," Folia Entomológica Mexicana, vol. 91, pp. 2330.

[33] I. Bhattacharjee, G. Aditya, and G. Chandra, "Laboratory and field assessment of the potential of larvivorous, air-breathing fishes as predators of culicine mosquitoes," Biological Control, vol. 49, no. 2, pp. 126-133, 2009.

[34] M. P. Hassell, J. H. Lawton, and J. R. Beddington, “The Components of Arthropod Predation: I. The Prey Death-Rate," Journal of Animal Ecology, vol. 45, no. 1, p. 135, 1976.

[35] C. Blois and A. Cloarec, "Density-dependent prey selection in the water stick insect, Ranatra linearis ( Heteroptera) ( Daphnia).," Journal of Animal Ecology, vol. 52, no. 3, pp. 849-866, 1983.

[36] S. E. Hampton, "Habitat overlap of enemies: Temporal patterns and the role of spatial complexity," Oecologia, vol. 138, no. 3, pp. 475-484, 2004.

[37] P. K. Das, N. Sivagnaname, and D. D. Amalraj, "Population interactions between Culex vishnui mosquitoes and their natural enemies in Pondicherry, India," Journal of Vector Ecology, vol. 31, no. 1, pp. 84-88, 2006.

[38] S. N. Chatterjee, A. Ghosh, and G. Chandra, "Eco-friendly control of mosquito larvae by Brachytronpratense larvae," Journal of Environmental Health, vol. 69, pp. 44-49, 2007.

[39] A. Venkatesh and B. K. Tyagi, "Capture efficiency of Bradinopyga geminata (Odonata: Libellulidae) against larvae of Aedes aegypti, Culex tritaeniorhynchus and Anopheles stephensi in laboratory condition," Journal of Basic and Applied Biology, vol. 7, no. 4, pp. 21-26, 2013.

[40] N. Saha, G. Aditya, S. Banerjee, and G. K. Saha, "Predation potential of odonates on mosquito larvae: Implications for biological control," Biological Control, vol. 63, no. 1, pp. 1-8, 2012. 


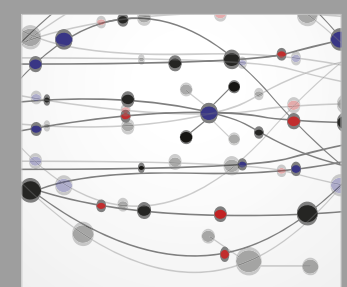

The Scientific World Journal
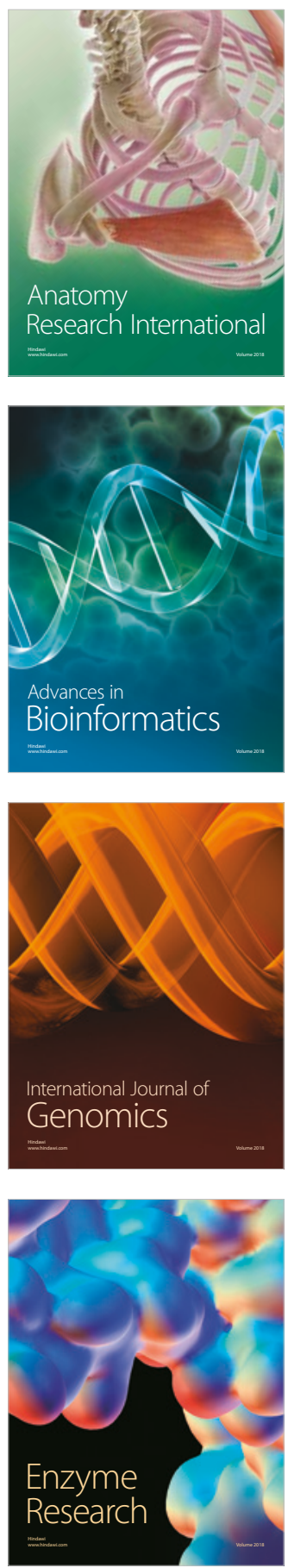
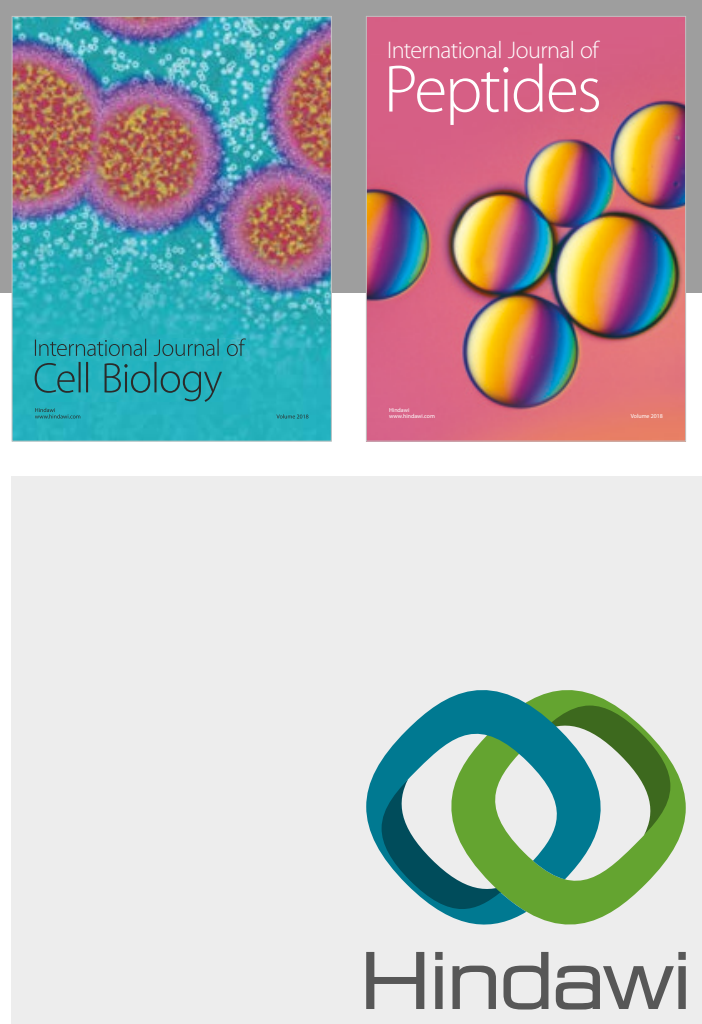

Submit your manuscripts at

www.hindawi.com
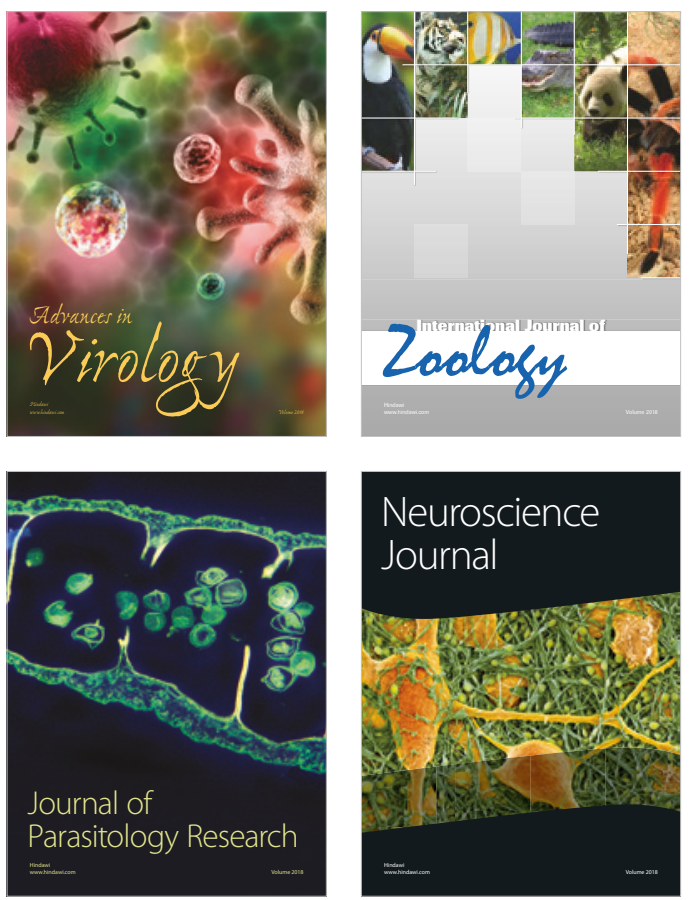
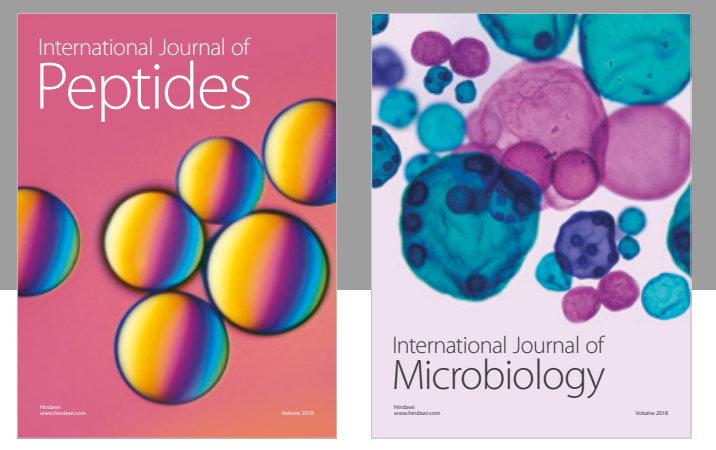

nternational Journal of Microbiology
Journal of
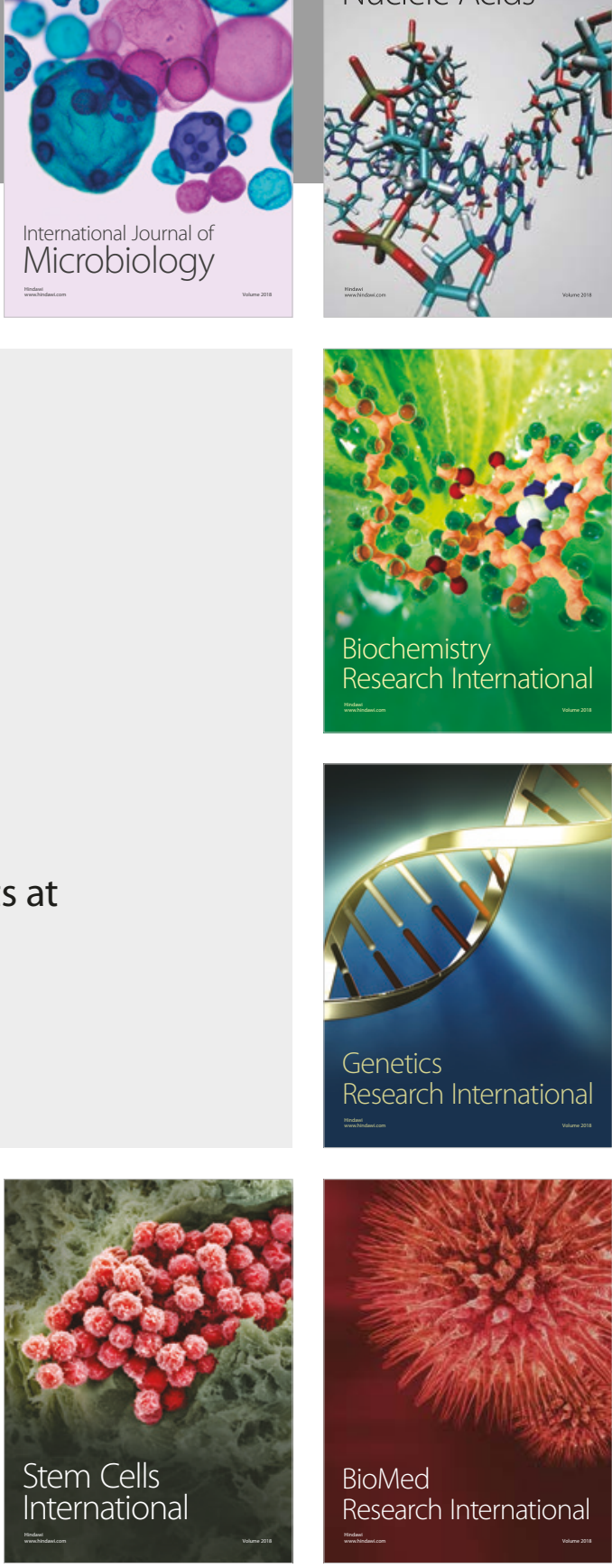
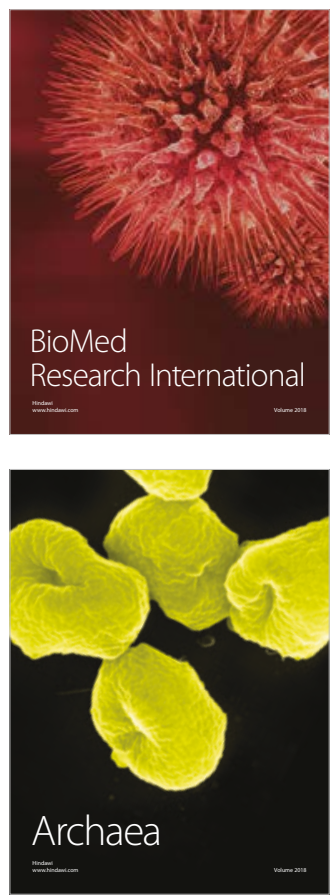